\section{Three lemming puzzles}

\section{Ilkka Hanski}

The Biology of Lemmings. Edited by Nils Christian Stenseth and Rolf Anker Ims. Academic Press: 1994. Pp. 683. £40, $\$ 99.95$.

WHEN the 23-year-old Charles Elton passed through the Norwegian town of Troms $\varnothing$ on his way back from an Arctic expedition in 1923, he spent much of his remaining money on a book by Robert Collett on Norwegian mammals. Elton
(D. Wilson and D. Reeder, Mammal Species of the World, 2nd edn, Smithsonian Institution Press, 1993). To their credit, however, they present an informative discussion on the genetic diversity in the problematic genus Dicrostonyx.

Of the three lemming puzzles, that of population dynamics receives most attention. So much has happened recently in the study of lemming dynamics and in rodent dynamics generally that the general framework provided here has become out of date. The current excitement about nonlinear rodent dynamics and the new approaches to modelling and data analysis are barely touched on in these pages.

Definite high points in this volume

\section{IMAGE \\ UNAVAILABLE FOR COPYRIGHT REASONS}

